\title{
PERANCANGAN JAM DIGITAL WAKTU SHOLAT MENGGUNAKAN ARDUINO UNO
}

\author{
Yusuf H. Kanoi ${ }^{1}$, Syahrir Abdussamad ${ }^{2}$, Sri Wahyuni Dali ${ }^{3}$ \\ ${ }^{123}$ Prodi Teknik Elektro Universitas Negeri Gorontalo \\ email: yusufh.kanoi@gmail.com, syahrirabdussamad@yahoo.co.id sri.dali@ung.ac.id
}

\begin{abstract}
Abstrak
Penelitian ini bertujuan untuk membuat Jam Digital Waktu Shalat Menggunakan Arduino Uno dan LED Dot Matrix P10 sebagai display dengan ukuran $16 x 32 \mathrm{~cm}$ sehingga dapat dilihat dari jarak jauh.Adapun metode perhitunganwaktu shalat yang digunakan dalam penelitian ini yaitu metode hisab rukyat, dimana rumus waktu shalat diprogram dan diproses secara otomatis didalam mikrokontroler, sehingga tidak perlu lagi untuk menginput atau memasukan data waktu shalat setiap tahunnya.Jam digital waktu shalat yang dibuat, sudah terealisasi dalam bentuk alat yang nyata, dilengkapi dengan fitur interface IR remote sebagai pengaturan parameter tampilan dan memiliki battery backup sebagai sumber catu daya cadangan ketika sumber catu daya dari power suply padam serta alarm waktu shalat apabila telah tiba, sehingga diharapkan dapat membantu umat muslim dalam melaksanakan shalat.
\end{abstract}

Kata kunci: Jam digital, Waktu shalat, Arduiono Uno, Dot matrix P10

\section{PENDAHULUAN}

Saat ini teknologi informasi semakin mengalami kemajuan yang sangat pesat. Teknologi informasi adalah suatu teknologi yang digunakan untuk mengolah data, termasuk memproses, mendapatkan, menyusun, menyimpan, memanipulasi data dalam berbagai cara untuk menghasilkan informasi yang berkualitas, efisien, tepat waktu dan menarik untuk dikonsumsi publik (Isnaeni, dkk, 2015: 2).

Perkembangan Teknologi Informasi memacu suatu cara baru dalam kehidupan, dimulai dari cara penentuan waktu dalam menyusun agenda pekerjaan, pendidikan, kesehatan serta membantu dalam menentukan waktu kewajiban kita seperti halnya shalat. Shalat merupakan salah satu rukun islam yang kedua, dimana shalat lima waktu ini wajib hukumnya atas setiap orang muslim yang beriman, seperti yang tercantum dalam Al- Qur'an Surah An Nisa ayat 103 yaitu: "Sesungguhnya shalat itu adalah kewajiban yang ditentukan waktunya atas orang-orang yang beriman".

Shalat lima waktu memiliki jadwal waktu yang sudah ditentukan sesuai ajaran Nabi Muhammad SAW, dimana waktu shalat ditentukan berdasarkan observasi terhadap gejala alam dengan melihat langsung matahari. Tetapi di zaman sekarang kita mengenal waktu shalat abadi 
Jambura Journal of Electrical and Electronics Engineering (JJEEE)

yang dikeluarkan oleh Departemen Agama

RI (Depag) yang isinya waktu shalat lima waktu dari bulan Januari sampai bulan Desember dan biasanya disertai koreksi waktu, perbedaan waktu antara daerah dengan cara menambah atau mengurang bilangan menit dengan nilai tertentu untuk wilayah yang berbeda.

Waktu shalat lima waktu yang diperoleh dari Depag maupun Organisasi keagamaan biasanya dalam bentuk cetakan atau print out yang dipajang di masjid atau mushola dan ada juga yang disertakan dalam kalender. Data ini merupakan acuan bagi para muazin untuk mengumandangkan adzan sebelum melakukan shalat fardlu berjamaah.Pengingat waktu sholat bisa juga dibuat dalam tampilan digital baik dalam bentuk perangkat lunak atau aplikasi maupun dalam bentuk alat atau perangkat elektronik yang menggunakan mikrokontroler sebagai pengontrolnya, seperti jam digital waktu shalat yang dijual ataupun yang terpajang di masjid- masjid.

Penelitian tentang jam digital waktu shalat menggunakan mikrokontroler sebelumnya sudah ada, namun masih perlunya pengembangan guna untuk memberikan efisiensi fungsi alat. Alat sebelumnya hanya menggunakan LCD 16x2 dan seven segmet sebagai display jam digital, sehingga masih sulit untuk dilihat dari jarak jauh.

Penelitian yang dilakukkan oleh Darmawan dkk, yang meneliti pada tahun 2013 dengan judul: "Rancang bangun Jam Digital Waktu Shalat Berbasis Mikrokontroler AT89S52”. Pada penelitian ini peneliti membuat rancang bangun jam digital waktu sholat berbasis mikrokontroler AT89S52 yang dapat memberikan informasi lengkap dan praktis dalam penunjukan akan waktu sholat yang bersesuaian dengan tanggal, bulan, tahun, serta 6 waktu sholat yang bersesuaian dengan tanggal yang bersangkutan. Dalam sistem yang dibuat menggunakan display tampilan 7 segmen berupa jam, menit, tanggal, bulan, tahun, dan 6 waktu shalat yang bersesuaian dengan tanggal. Penelitian ini menghasilkan sistem jam digital waktu shalat yang mengunakan 7 segmen sebagai display,RTC sebagai real time clock, buzzer sebagai alarm, dan Eeprom AT24C32 sebagai memori eksternal. Eeprom AT24C32 digunakan untuk menyimpan data base jadwal waktu shalat selama 1 tahun. Dalam sistem jam digital waktu sholat ini menggunakan daftar jadwal sholat yang bersumber dari RHI (Rukyatul Hilal Indonesia), web 
http://rukyatulhilal.org.

\section{METODE PENELITIAN}

Pada penelitian ini dilakukan eksperimen secara langsung dalam membuat alat serta melakukan pengujian.Pada metode eksperimen dilakukan perancangan sistem. Perancangan sistem terbagi atas dua yaitu, pengujian terhadap program (sketch) dan hardwareapakah bekerja dengan baik atau tidak.

Perhitungan Waktu Shalat Metode perhitunganwaktu shalat (hisab rukyat) yang digunakan dalam penelitian ini, dimana rumus waktu shalat diprogram kedalam mikrokontroler dan diproses secara otomatis didalam mikrokontroler, sehingga tidak perlu lagi untuk menginput atau memasukan data waktu shalat setiap tahunnya.

\section{HASIL DAN PEMBAHASAN}

\section{Pengujian Program}

Pada perancangan jam digital waktu shalat menggunakan Arduino Uno ini, terdiri dari beberapa bagian rangkaian yang kemudian digabung menjadi satu skema alat secara keseluruhan, sehingga hasil gabungan rangakaian ini membentuk suatu alat yang utuh dan diharapkan dapat bermanfaat untuk umat muslim yang ingin melaksanakan shalat. Adapun skema dan rangkaian alat secara keseluruhan dari jam digital waktu shalat ini, dapat dilihat pada Gambar 1 dan Gambar.2.

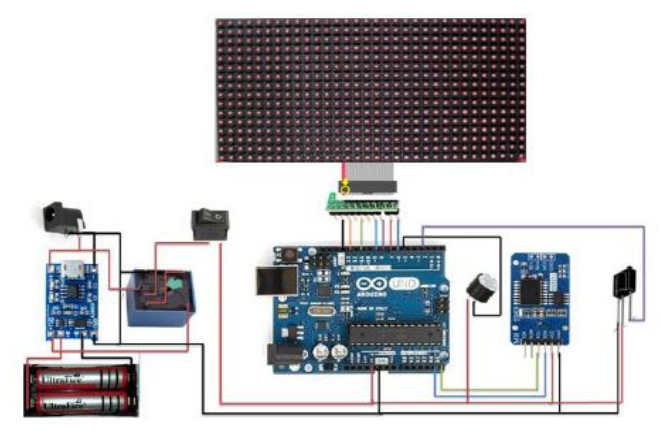

Gambar 1. Skema Alat secara keseluruhan.

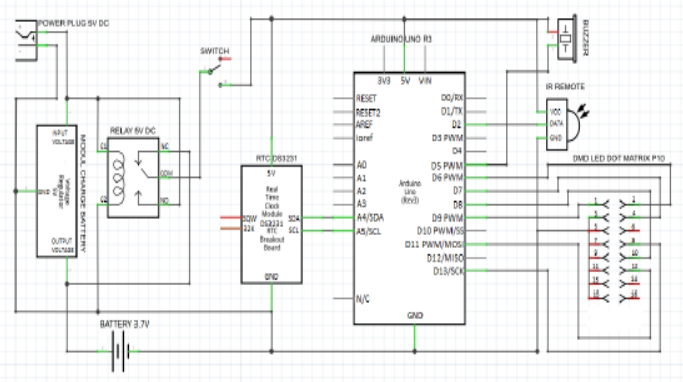

Gambar 2 Rangkaian Alat secara keseluruhan

Pengujian ini bertujuan untuk mengetahui apakah program yang akan di upload kedalam mikrokontroler arduino, sudah benar atau masih terjadi kesalahan (error), sehingga perlu adanya verify atau pengecekan program terlebih dahulu sebelum di upload kedalam mikrokontroler. Tampilan program selesai di compile dapat dilihat pada Gambar 3.

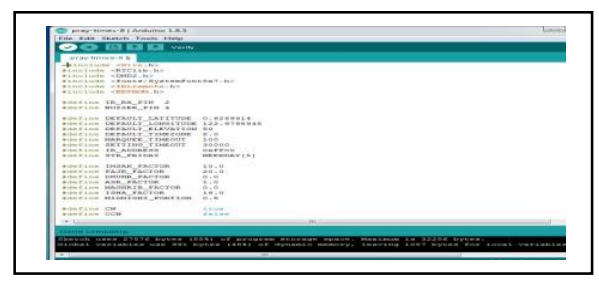

Gambar 3. Tampilan programsetelah diverifikasi 
Pada Gambar 3. menunjukan bahwa program yang dibuat berhasil di verifikasi dengan keterangan (Done compiling) sehingga program sudah bisa di upload kedalam mikrokontroler.

\section{Pengujian respon ir remote terhadap tampilan.}

Pada pengujian respon $I R$ remote terhadap tampilan dilakukan secara berkala untuk memastikan apakah IR remote berfungsi dengan baik atau tidak.Pengujian ini berfungsi untuk keperluan pengaturan parameter-parameter tampilan seperti Jam, Menit, Hari, Tanggal, Bulan, Tahun, Lintang, Bujur, Zona waktu, dan Elevasi atau ketinggian suatu tempat.

\section{Pengujian Tampilan Jam Digital}

Sebelum dilakukan pengujian tampilan jam digital pada LED dot matrix P10, alangkah baiknya terlebih dahulu mengetahui bagianbagian dari tampilan LED dot matriks P10 dari jam digital ini. Tampilan LED dot matriks ini terbagi atas dua bagian tampilan yaitu: Tampilan bagian atas dan tampilan bagian bawah. Pada bagian tampilan atas yaitu jam dan menit sebagai tampilan defaultnya, sedangkan tampilan pada bagian bawah yaitu tampilan informasi seperti suhu, hari, tanggal, bulan dan tahun serta tiga waktu shalat ditampilkan secara bergantian, dengan pergeseran teks kearah kiri seperti diperlihatkan pada gambar 4 .

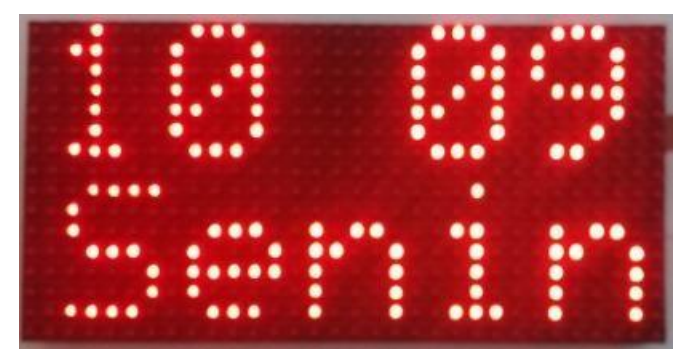

Gambar 4. Tampilan Jam Digital Waktu Shalat

Apabila waktu shalat telah tiba, maka akan muncul tampilan "Waktunya shalat yang bersangkutan" selama 5 menit ditandai dengan bunyi alarm selama satu menit, serta diikuti oleh tampilan suhu, hari, tanggal, bulan dan tahun.

\section{Pengujian Waktu Shalat}

Pengujian waktu shalat dilakukan untuk memastikan apakah waktu shalat yang ditampilkan pada jam digital bersesuaian dengan waktu shalat yang berlaku di wilayah Kota Gorontalo. Jadwal waktu shalat pada jam digital pada penelitian ini, kompatibel atau bersesuaian dengan jadwal shalat yang bersumber dari http://zulns.github.io/prayertimes/mont hly.html sehingga data waktu shalat dapat diakses langsung pada website tersebut. 
Jambura Journal of Electrical and Electronics Engineering (JJEEE)

Sedangkan jadwal waktu shalat yang di jadikan perbandingan yaitu jadwal waktu shalat dari Kementrian Agama yang bersumberdari http://simbi.kemenag.go.id.

\section{Pengujian Alarm Waktu Shalat}

Pengujian Alarm waktu shalat ini bertujuan untuk mengetahui apakah alarm waktu shalat berfungsi dengan baik atau tidak, sehingga perlu dilakukan pengujian terhadap alarm waktu shalat tersebut. Adapun pengujian alarm ini dapat dilihat pada Tabel di bawah ini.

Tabel 1. Pengujian Alarm Waktu Shalat

\begin{tabular}{|c|c|c|c|c|}
\hline \multirow{2}{*}{ No } & \multicolumn{2}{|c|}{ PARAMETER } & \multicolumn{2}{|l|}{ HASIL PENGUJIAN } \\
\hline & TGL & JAM & $\begin{array}{c}\text { LED DOT } \\
\text { MATRIX }\end{array}$ & $\begin{array}{l}\text { ALARM / } \\
\text { BUZZER }\end{array}$ \\
\hline 1. & $\begin{array}{l}2 \mathrm{Mei} \\
2018\end{array}$ & $04: 10$ & Tampilan default & Tidak aktif \\
\hline 10 & $\begin{array}{l}2 \mathrm{Mei} \\
2018\end{array}$ & $04: 22$ & $\begin{array}{c}\text { Waktunya shalat } \\
\text { subuh }\end{array}$ & $\begin{array}{l}\text { Aktif selama } \\
1 \text { menit }\end{array}$ \\
\hline 15 & $\begin{array}{l}2 \mathrm{Mei} \\
2018\end{array}$ & $04: 27$ & Tampilan default & $\begin{array}{l}\text { Tidak } \\
\text { aktif }\end{array}$ \\
\hline 16 & $\begin{array}{l}2 \mathrm{Mei} \\
2018\end{array}$ & $11: 44$ & Tampilan default & $\begin{array}{l}\text { Tidak } \\
\text { aktif }\end{array}$ \\
\hline 17 & $\begin{array}{l}2 \mathrm{Mei} \\
2018\end{array}$ & $11: 45$ & $\begin{array}{c}\text { Waktunya shalat } \\
\text { dzuhur }\end{array}$ & $\begin{array}{l}\text { Aktif selama } \\
1 \text { menit }\end{array}$ \\
\hline 23 & $\begin{array}{l}2 \mathrm{Mei} \\
2018\end{array}$ & $15: 05$ & Tampilan default & $\begin{array}{l}\text { Tidak } \\
\text { aktif }\end{array}$ \\
\hline 24 & $\begin{array}{l}2 \mathrm{Mei} \\
2018 \\
\end{array}$ & $15: 06$ & $\begin{array}{l}\text { Waktunya } \\
\text { shalat ashar }\end{array}$ & $\begin{array}{c}\text { Aktif selama } \\
1 \text { menit }\end{array}$ \\
\hline 29 & $\begin{array}{l}2 \mathrm{Mei} \\
2018\end{array}$ & $15: 11$ & $\begin{array}{l}\text { Tampilan } \\
\text { default }\end{array}$ & Tidak aktif \\
\hline 30 & $\begin{array}{c}2 \\
\text { Mei } \\
2018\end{array}$ & $17: 49$ & $\begin{array}{l}\text { Tampilan } \\
\text { default }\end{array}$ & Tidak aktif \\
\hline 31 & $\begin{array}{c}2 \\
\text { Mei } \\
2018\end{array}$ & $17: 50$ & $\begin{array}{l}\text { Waktunya shalat } \\
\text { magrib }\end{array}$ & $\begin{array}{l}\text { Aktif selama } \\
1 \text { menit }\end{array}$ \\
\hline 32 & $\begin{array}{c}2 \\
\text { Mei } \\
2018\end{array}$ & $17: 51$ & $\begin{array}{l}\text { Waktunya shalat } \\
\text { magrib }\end{array}$ & $\begin{array}{l}\text { Aktif selama } \\
1 \text { menit }\end{array}$ \\
\hline 37 & $\begin{array}{c}2 \\
\mathrm{Mei} \\
2018\end{array}$ & $19: 00$ & $\begin{array}{l}\text { Tampilan } \\
\text { default }\end{array}$ & Tidak aktif \\
\hline 38 & $\begin{array}{c}2 \\
\text { Mei }\end{array}$ & 19:01 & $\begin{array}{l}\text { Waktunya } \\
\text { shalat isya }\end{array}$ & $\begin{array}{c}\text { Aktif selama } \\
1 \text { menit }\end{array}$ \\
\hline
\end{tabular}

\begin{tabular}{|r|c|c|c|c|}
\hline & 2018 & & & \\
\hline 39 & 2 & $19: 02$ & $\begin{array}{c}\text { Waktunya } \\
\text { shalat isya }\end{array}$ & $\begin{array}{c}\text { Aktif selama } \\
1 \text { menit }\end{array}$ \\
& $\begin{array}{c}\text { Mei } \\
2018\end{array}$ & & $\begin{array}{c}\text { Waktunya } \\
\text { shalat } \\
\text { tengah } \\
\text { malam }\end{array}$ & Tidak aktif \\
\hline 46 & 2 & $23: 46$ & Tampilan & Tidak aktif \\
& Mei & & default & \\
& 2018 & & & \\
\hline 51 & 2 & $00: 00$ & & \\
& & & \\
& & & & \\
& & & & \\
\hline
\end{tabular}

Dari hasil pengujian alarm waktu shalat diatas diperoleh bahwa alarm akan aktif apabila sudah tiba waktu shalat subuh, dzuhur, ashar, magrib dan isya', sedangkan untuk waktu shalat tengah malam dan imsak alarm tidak aktif atau tidak berbunyi. Cara kerja dari alarm ini berlaku juga untuk hari dan tanggal selanjutnya.

\section{Pengujian Catu Daya dan Battery Backup}

Pengujiancatu dayadan battery backup ini bertujuan untuk mengetahui kehandalan catu dayaterhadap tampilan jam digital. Adapun pengujian catu dayadan battery backup ini dapatdilihat pada Tabel 2 dan Tabel 3.

Tabel 2. Pengisian Battery Backup

\begin{tabular}{|c|c|}
\hline $\begin{array}{c}\text { Waktu } \\
\text { Pengisian }\end{array}$ & $\begin{array}{c}\text { Tegangan } \\
\text { Pengisian }\end{array}$ \\
\hline 0 & 0,18 \\
\hline 1 & 0,94 \\
\hline 2 & 1,70 \\
\hline 3 & 2,46 \\
\hline 4 & 3,22 \\
\hline 5 & 3,98 \\
\hline 6 & 4,15 \\
\hline 7 & 4.20 \\
\hline
\end{tabular}


Pada Tabel 2.dapat dilihat bahwa pengisian baterry membutuhkan waktu 7 jam dengan tegangan pengisian dari $0,18-4,20 \mathrm{~V}$ dalam keadaan jam digital beroperasi.

Tabel 3. Pengosongan Battery Backup

\begin{tabular}{|c|c|}
\hline $\begin{array}{c}\text { Waktu } \\
\text { Pengosongan }\end{array}$ & $\begin{array}{c}\text { Tegangan } \\
\text { Pengosongan }\end{array}$ \\
\hline 0 & 4,20 \\
\hline 1 & 4,15 \\
\hline 2 & 4,10 \\
\hline 3 & 2,60 \\
\hline 4 & 1,55 \\
\hline 5 & 1,50 \\
\hline 6 & 0,45 \\
\hline 7 & 0,40 \\
\hline 8 & 0,10 \\
\hline 9 & 0,05 \\
\hline 10 & 0 \\
\hline
\end{tabular}

Pada Tabel 3. dapat dilihat bahwa pengosongan battery backup membutuhkan waktu selama 24 jam.

\section{PEMBAHASAN}

Berdasarkan permasalahan yang terdapat pada penelitian sebelumnya yakni masih perlunya pengembangan terhadap tampilan jam digital waktu shalat yang masih menggunakan penampil LCD 16x2 dan 7 segment, maka peneliti berinisiatif untuk membuat jam digital waktu shalat dengan ukuran tampilannya berbeda dengan penelitian sebelumnya yaitu menggunakan LED dot matrix P10, dimana ukuran dari display ini adalah $32 \times 16 \mathrm{~cm}$, sehingga dapat dijangkau dari jarak jauh. Adapun perhitungan dari jam digital waktu shalat ini menggunakan metode perhitungan waktu shalat (hisab rukyat) yang diprogram langsung kedalam mikrontroler dan diproses secara otomasis, sehingga tidak perlu lagi memasukkan data base waktu shalat setiap tahunnya.

Jam digital waktu shalat ini juga dilengkapi antarmuka IR remote sebagai pengaturan paremeter tampilan dengan respon yang cepat dan tepat dalam jarak jangkauan $\pm 7 \mathrm{~m}$, serta dilengkapi dengan battery backup yang berfungsi sebagai sumber catu dayacadangan apabila sumber dari power suply mati, maka battery backup inilah yang akan menggantikan sumber catu daya agar jam digital akan tetap beroperasi dalam beberapa jam kemudian.

\section{KESIMPULAN DAN SARAN}

\section{Kesimpulan}

Berdasarkan hasil penelitian yang dilakukan dapat disimpulkan, bahwa jam digital waktu shalat yang dibuat dapat terealisasi dalam bentuk alat yang nyata, dan dilengkapi dengan fitur interface IR remote sebagai 
Jambura Journal of Electrical and Electronics Engineering (JJEEE)

pengaturan parameter tampilan serta memiliki battery backup sebagai sumber catu daya cadangan ketika sumber catu daya dari power suply padam.

Cara kerja dari jam digital waktu shalat ini yakni, terbagi atas dua bagian tampilan. Tampilan pertama sebagai jam dan menit sebagai default dan tampilan kedua yaitu tampilan informasi seperti, suhu, hari, tanggal, bulan, tahun, serta diikuti oleh tampilan tiga waktu shalat dengan pergeseran tampilan ke kiri secara bergantian, serta memiliki alarm atau pengingat apabila waktu shalat sudah tiba.

\section{Saran}

Pada hasil penelitian yang telah dilakukan terdapat beberapa saran, antara lain:Sebaiknya jadwal waktu shalat sudah ditambah dengan iktiyat atau waktu untuk kehati-hatian, agar sesuai dengan jadwal waktu shalat yang berlaku di Wilayah Kota Gorontalo.

Alarm waktu shalat perlu dikembangkan lagi dengan menggunakan suara adzan, sebagai pengingat datangnya waktu shalat, serta antarmuka pengaturan parameter tampilan perlu ditingkatkan lagi agar jarak jangkauannya luas, misalnya menggunakan bluetooth atau Wi-Fi
(Wireless Fidelity)

\section{REFERENSI}

[1] Anugraha, R. 2012. Mekanika Benda Langit.Jurusan Fisika Fakultas MIPA Universitas Gadjah Mada. Yogyakarta.

[2] Arifin, J., L.N Zulita, dan Hermansyah. 2016. Perancangan Murottal Otomatis MenggunakanMikrokontroler Arduino Mega 2560. Jurnal Media Infotama. 12 (1): 89-98.

[3] Darmawan,Sudjadi dan

Darjat.2013.Rancangan Bangun Jam Digital Waktu Shalat Berbasis Mikrokontroler AT89S52.TRANSIENT. 2(2):269-274.

[4] http://zulns.github.io/prayertimes/monthly.html. Diakses $01 \mathrm{Mei}$ 2018.

[5] https://bimasislam.kemenag.go.i d/jadwalshalat. Diakses 01 Mei 2018

[6] Isnaeni, D. M., F. Mintarsih \& F. Fahrianto. 2015. Implementasi Algoritma Meeus

Dalam Penentuan Waktu Shalat Dan Pencarian Masjid Terdekat. Jurnal Sistem Informasi. Universitas Islam Negeri Syarif Hidayatullah Jakarta, Indonesia.

[7] Kadir, A. 2012. Panduan Praktis Memperlajari Aplikasi Mikrokontroler dan Pemogramannya menggunakan 
Arduino. Edisi Pertama. Jilid 1. ANDI. Yogyakarta.

[8] Kadir, A. 2014. From Zero to A Pro Arduino. Edisi Pertama. Jilid 2. ANDI Yokyakarta.

[9] Khamdani. 2014. Rancang Bangun Running Text Led Didplay Berbasis Mikrokontroler Sebagai Media Informasi Di Universitas Muhamadiyah Purwokerto.Skripsi. Program Studi

Teknik Elektro Universitas
Muhammadiyah. Purwokerto.

[10] Santoso, H. 2015. Panduan Praktis Arduino Untuk Pemula. Ebook Versi 1. Www.elangsakti.com.

[11] Sutinah, E. 2016. Sistem Informasi Penjadwalan Waktu Sholat Berbasis Mikrokontroler Atmega16. Informatics for Educators and Professional. 1 (1): 37- 50. 